\title{
LA SENSIBILIDAD INTERCULTURAL EN PAULO FREIRE ${ }^{1}$
}

\author{
Dra. Nubia Cecília Agudelo Cely ${ }^{2}$ \\ Universidad Pedagógica y Tecnológica de Colombia \\ Grupo de Investigación HISULA \\ nubia.agudelo@uptc.edu.co \\ Dr. Norman Estupiñán Quiñones ${ }^{3}$ \\ Universidad Pedagógica y Tecnológica de Colombia \\ Grupo de Investigación HISULA \\ norman4219@hotmail.com
}

Recepción: 04/09/2009

Evaluación: 15/09/2009

Aceptación: 07/10/2009

Artículo de Reflexión

\section{RESUMEN}

El sentido y el significado de las relaciones con los otros se convirtieron en eje articulador del pensamiento y de las prácticas educativas de Paulo Freire. Desde esta perspectiva se desentrañan las conceptualizaciones y el valor asignado a la sensibilidad intercultural, entendida como proyección y respuestas emocionales positivas frente a los demás, fomento de la curiosidad profunda y del pensamiento crítico, al igual que el respeto y la valoración de mundo, intereses y saberes de los otros; las ideas expuestas se convierten en el objetivo primordial de esta artículo, para ello se revisaron obras

\footnotetext{
1 El artículo surge de la investigación inscrita institucionalmente en la Universidad Pedagógica y Tecnológica de Colombia, Sentido y significaciones de la Interculturalidad en las Universidades de RUDECOLOMBIA. A la vez el presente artículo fue presentado en el Simposio de Educadores Latinoamericanos, en el marco del VII Congreso Internacional de la Sociedad de Historia de la Universidad Latinoamericana, Sao Paulo (Brasil), agosto de 2009 en donde este gran pedagogo tiene un espacio.

2 Doctora en Ciencias de la Educación de RUDECOLOMBIA, profesora Universidad Pedagógica y Tecnológica de Colombia. Coordinadora del grupo de investigación Construyendo Comunidad Educativa e integrante del grupo HISULA.

3 Doctor en Ciencias de la Educación de RUDECOLOMBIA, Profesor Universidad Pedagógica y Tecnológica de Colombia. Coordinador del grupo de investigación Urdimbre Cultural e integrante del grupo HISULA.
} 
fundamentales de Freire, tales como, pedagogía del oprimido, Pedagogía de la esperanza y Pedagogía de la autonomía, sin menoscabo, naturalmente, de otros autores $\mathrm{y}$ argumentos que sirvieron como apoyo a las anteriores producciones.

Palabras clave: Sensibilidad Intercultural, Curiosidad Profunda, Pensamiento Crítico, Diálogo de Saberes, Pensamiento de Frontera, Preocupación por el Otro.

\title{
THE INTERCULTURAL SENSITIVITY IN PAULO FREIRE
}

\author{
Dra. Nubia Cecília Agudelo Cely \\ Universidad Pedagógica y Tecnológica de Colombia \\ HISULA Research Group \\ nubia.agudelo@uptc.edu.co \\ Dr. Norman Estupiñán Quiñones \\ Universidad Pedagógica y Tecnológica de Colombia \\ HISULA Research Group \\ norman4219@hotmail.com
}

\begin{abstract}
Sense and meaning of relationship with others become a thought articulator axle and Paulo Freire's educational practices as well. From this perspective, the conceptualizations and the cultural value assigned to the cultural sensibility stem from them. Such a cultural sensitivity is understood as projection and positive emotional answers as to others, deep curiosity promotion, critical thought, respect and world appraisal, and others' interests and knowledge. The ideas exposed become a primordial objective of this presentation. For that, fundamental Freire's work was revised, such as Pedagogía del Oprimido, Pedagogía de la Esperanza, y Pedagogía de la autonomía, as well as, of course, revision of other autors and arguments, which served as support for the previous publications.
\end{abstract}

Key word: Intercultural Sensitivity, Deep Curiosity, Critical Thought, Dialogue of Learnings, Frontier Thought, and Worry About Others. 
Nubia Agudelo - Norman Estupiñan

El sujeto que se abre al mundo y a los otros inaugura con su gesto

la relación dialógica en que se confirma como inquietud y curiosidad, como inconclusión en permanente movimiento en la Historia.

Paulo Freire

Pedagogía de la Autonomía

\section{INTRODUCCIÓN}

El universo del pensamiento y de la práctica educativa de Paulo Freire a diario se encuentra nuevas perspectivas y nuevas posibilidades. El interés primordial que nos anima en esta ocasión, es la posibilidad de develar la sensibilidad intercultural en obras de este autor, como son Pedagogía del oprimido, Pedagogía de la esperanza y Pedagogía de la autonomía. El abordaje de temas como la curiosidad profunda, el pensamiento crítico y de frontera, el diálogo de saberes y la preocupación por los otros, son sometidos a análisis y ponderación, orientados a visibilizar la dimensión intercultural que subyace en la obra de este gran pedagogo latinoamericano. Por lo tanto, cada uno de los temas tendrá su tratamiento específico, y se señalará el valor y la vigencia de los tópicos estudiados, que sirvan como elementos referenciales para seguir profundizando en ellos por medio de la investigación y la reflexión permanente.

\section{Fomento de la Curiosidad Profunda}

Sin duda, la preocupación fundamental que le da sentido y significado a la vida y a la obra de Paulo Freire está fundamentada y relacionada con la existencia del otro. El ser humano en él, es eminentemente relacional, pero esa relacionalidad con el otro debe estar signada por la búsqueda de la coexistencia humana y con una organización social que la haga posible. En este sentido, el acto de enseñar y de aprender es un espacio signado por el encuentro pedagógico que hace posible que los humanos puedan entrar en un diálogo permanente para crecer en humanidad; porque, y es conveniente recalcarlo, que sólo es posible dialogar cuando hay variedad de lógicas de sentido, cuando hay diversas sensibilidades donde el vivir y el ser se hacen patentes en tramas existenciales distintas, y cuando, los horizontes de perspectivas interpretativas toman dimensiones divergentes y morfologías particulares en el marco de las experiencias humanas.

Esta propuesta es apoyada por David Bohm, cuando expresa: "El diálogo hace posible, en suma, la presencia de una corriente de significado en el seno del grupo, a partir de la cual puede emerger una nueva comprensión, algo creativo que no se hallaba, en modo alguno, en el momento de partida. Y este significado compartido es el «aglutinante», el «cemento» que sostiene los vínculos entre las personas y entre las sociedades." ${ }^{4}$

4 BOHM, David. (1997): Sobre el diálogo, Barcelona, Editorial Kairós, p. 30. 
En este aspecto consideramos de interés, igualmente, vincular algunas ideas propuestas por León Vega: "Estos modos, que son de hecho capacidades constituyentes, se entreverán en nuestros ángulos de visibilidad respecto al mundo, en nuestras discursividades y sistemas de nominación, así como en nuestras estructuras de sensibilidad, para delimitar las fronteras más básicas entre lo que somos o suponemos que somos; con respecto a lo que son, o suponemos que son, aquellos otros seres que visitan nuestra experiencia diaria con su radical singularidad"s.

En la misma dirección, Freire, hace notar que:

El diálogo es una exigencia existencial. Y siendo el encuentro que solidariza la reflexión y la acción de sus sujetos encauzados hacia el mundo que debe ser transformado y humanizado, no puede reducirse a un mero acto de depositar ideas de un sujeto en el otro, ni convertirse tampoco en un simple cambio de ideas consumadas por sus permutantes. ${ }^{6}$

Entonces, el diálogo es intencional, es una acción encaminada al crecimiento, a la búsqueda de ser más, para instalarnos en las cosmovisiones de lo propio y de lo ajeno. Es además, una perspectiva humana que no puede prescindir de la condición del hombre, que no sólo consulta a su referente lógico, sino a todo su potencial vital. Por eso, el sujeto que dialoga está convencido que se ganarán en el proceso otras dimensiones y otras cualidades que antes no se tenían.

Pero también es digno de anotar, como dice Geoffrey Lloyd: "pero no todos los seres humanos parecen experimentar la urgente necesidad de aumentar o, al menos, someter a prueba el caudal existente de conocimiento, sino que muchos se muestran, más bien, satisfechos con el saber heredado, con lo que se les dice que deben creer."

En este sentido, el encuentro pedagógico y el diálogo concomitante que se establezca en él, estará orientado al fomento de la curiosidad profunda como una de las cualidades de la sensibilidad intercultural. Esta perspectiva reconoce y fomenta los espacios compartidos de convivencia y de interrelaciones entre diferentes expresiones culturales, ya que éstas no son estáticas, sino eminentemente dinámicas, y es precisamente esa permeabilidad en su constante devenir, lo que hace que puedan intercambiar cosmovisiones, costumbres, conocimientos y pareceres. En el sentido de Panikkar, "La fluidez de la cultura es lo que permite la interculturalidad". Y sigue diciendo el mismo autor: "El diálogo intercultural se da en la conversación entre personas y no entre individuos, en cuanto que no se trata sólo de un diálogo individual entre dos seres

\footnotetext{
5 LEÓN VEGA, Emma. (2005): Sentido ajeno. Competencias ontológicas y otredad, Barcelona, Anthropos, p. 7.

6 FREIRE, Paulo. (1998): Pedagogía del Oprimido, México, Siglo XXI Editores, p. 101.

7 LLOYD, Geoffrey. (2008): Las aspiraciones de la curiosidad. La comprensión del mundo en la antigüedad: Grecia y China, España, Siglo XXI Editores. p. 1.
} 
humanos desarraigados de su substrato y de su historia, sino de una ósmosis entre dos visiones de la realidad, más aún entre dos mundos, por así decirlo, por dos personas humanas que llevan consigo todo el peso (la historia) de sus culturas."

Esta es también la mirada de Paulo Freire: "El diálogo es ese encuentro de los hombres, mediatizado por el mundo, para pronunciarlo no agotándose, por lo tanto, en una mera relación yo-tú "' . Es en ese diálogo pedagógico en donde el fomento de la curiosidad profunda tiene sentido y significación. Esa curiosidad que mantiene a los individuos en estado de incertidumbre para desarrollar habilidades investigativas y para crear, mantener y resolver conflictos conceptuales e interculturales; esa curiosidad, abre, por lo tanto, un espacio de diálogo intercultural, en donde las valoraciones de los demás son elementos primordiales para su fomento. En este sentido, Paulo Freire, presenta una propuesta de alta significación:

El buen clima pedagógico-democrático es aquel en el que el educando va aprendiendo, a costa de su propia práctica, que su curiosidad como su libertad debe estar sujeta a límites, pero en ejercicio permanente. Límites asumidos éticamente por él. Mi curiosidad no tiene derecho de invadir la privacidad del otro y exponerla a los demás. ${ }^{10}$

Entonces, el enseñar y el aprender requieren del ejercicio de la curiosidad profunda. De esta manera, el derecho a la curiosidad se hace palpable. Esta curiosidad, de la misma manera, es un elemento indispensable para la indagación y para la producción de conocimiento, porque ese acto se convierte en eje orientador de la búsqueda. Y es que preguntar es concomitante con la condición humana y está directamente ligada con la curiosidad, ligazón ésta que inquiere por el sentido de su ser social, ético, pedagógico y de convivencia intercultural; en palabras de Freire:

El ejercicio de la curiosidad la hace más críticamente curiosa, más metódicamente "perseguidora" de su objeto. Cuanto más se intensifica la curiosidad espontánea, pero sobre todo, cuanto más se "rigoriza", tanto más epistemológica se va volviendo. ${ }^{11}$

En fin, el ejercitar constante de la curiosidad, aunado con el acicate permanente del preguntar, van conduciendo a la configuración de una actividad pedagógica que estimula la reflexión crítica y un pensamiento fecundo que vaya más allá de la asimilación pasiva y de las "respuestas que esterilizan burocráticamente."12

8 PANIKKAR, Raimon. (2006): Paz e Interculturalidad, una reflexión filosófica, España, Herder Editorial. p. 27

9 FREIRE, Paulo. (1998). Op. Cit, p. 101.

${ }^{10}$ FREIRE, Paulo. (1998): Pedagogía de la autonomía, México, Siglo XXI Editores, p. 82.

11 Ibídem, p. 84.

12 Ibídem, p. 83. 


\section{Promoviendo el Pensamiento Crítico}

El preguntar y el ejercicio de la curiosidad, indefectiblemente conducirán a promover y a fomentar el pensamiento crítico expreso en las obras de Paulo Freire, pero estos aspectos que estamos analizando no se dan en él en forma lineal, sino que hacen parte de una madeja de pensamiento, que para hacer más sistemático el proceso, lo presentamos en estas condiciones. Así el concepto de pensamiento crítico está inscrito dentro de una categoría mayor, como es la Pedagogía crítica. Ésta como corriente pedagógica significativa, busca reflexionar y problematizar la educación para que sirva como elemento fundamental del cambio y la transformación. En este sentido, la propuesta de Paulo Freire, es de un valor y de una vigencia a todas luces:

El pensar acertadamente sabe, por ejemplo, que no es a partir de él, como un dato dado, como se conforma la práctica docente crítica, sino que sabe también que sin él ésta no se funda. La práctica docente crítica, implícita en el pensar acertadamente, encierra el movimiento dinámico, dialéctico entre el hacer y el pensar sobre el hacer. El saber que indiscutiblemente produce la práctica docente espontánea o casi espontánea, "desarmada", es un saber ingenuo, un saber hecho de experiencia, al que le falta el rigor metódico que caracteriza a la curiosidad epistemológica del sujeto. Éste no es el saber que busca el rigor del pensar acertadamente. Por eso es fundamental que, en la práctica de la formación docente, el aprendiz de educador asuma que el indispensable pensar acertadamente no es una dádiva de los dioses ni se encuentra en los manuales de los profesores que intelectuales iluminados escriben desde el centro del poder, sino que, por lo contrario, el pensar acertadamente que supera al ingenuo tiene que ser producido por el mismo aprendiz en comunión con el profesor formador. ${ }^{13}$

En este sentido, el pensamiento crítico como un espacio que permite darle significaciones a las experiencias vitales, no puede realizarse en el vacío, sino dentro de una matriz de sentido, tiene, por lo tanto, un marco de significación que hace posible examinar relaciones lógicas, identificar diferentes perspectivas y valorar procesos para ponderar lo relevante de lo que no lo es. Pero esa estructura formal debe tener un contenido, que en nuestro proceso de análisis está signado por las relaciones de los encuentros pedagógicos en los espacios formativos de sujetos sociales. Es aquí en donde la Pedagogía y el pensamiento crítico se evidencian. Es aquí en donde el pensamiento de Paulo Freire es un aporte creativo que permite incentivar aprendizajes y redimensionar las relaciones pedagógicas entre docentes y aprendices para reinterpretar la realidad y proyectar nuevas perspectivas de cambio.

Pensadores actuales como Jacques Boisvert y Agustin Campos Arenas, también comparten las apreciaciones de Paulo Freire. El primero afirma: "El pensamiento crítico comprende las capacidades y actitudes que desempeñan el papel principal en el proyecto

13 Ibídem, pp. 39-40. 
de analizar y dominar las innumerables informaciones que caracterizan el contexto social actual."14 Mientras que el segundo apunta: "Si bien el desarrollo y cultivo del pensamiento crítico se da en todo tipo de escenario, es la escuela el más propicio, aunque se le acusa de no haber cumplido con esta finalidad al enfatizar la memorización y la reproducción de información." 15

El proceso de cambio, es entonces, ese tránsito desde la conciencia ingenua hacia la conciencia crítica, en este transcurrir, el sujeto en formación, que lo es, tanto el profesor como el estudiante, necesitan de una metamorfosis formativa, es decir, se tiene que construir como sujeto, en otras palabras, tiene que producir un entramado de percepciones, saberes, pensamientos, memoria y sentimientos que le permitan afianzarse en el mundo en el devenir relacional con los otros. En este sentido, el sujeto es concebido como un producto de la interrelación entre sus "pertenencias experienciales" y la matriz cultural en la cual vive, lo que le permite que construya, en ese proceso histórico de interrelaciones, su subjetividad, como urdimbre de significados para ejercer su autonomía.

Para Paulo Freire la formación de sujetos autónomos es un compromiso éticopolítico que se necesita asumir para cambiar estructuras de pensamiento en lo epistemológico-didáctico-pedagógico, para producir conocimiento y pensar lo inédito viable, ya que el conocimiento es producción de sentido y es capacidad de nombrar el mundo para transformarlo.

Entonces, los espacios formativos rescatan al otro como sujetos sociales que tejen sus tramas en intercambios culturales para tomar decisiones en la madeja participativa alimentada por la plasticidad de la comunicación. En ese intercambio vivencial, se van aprendiendo a potenciar las transformaciones, se va tomando conciencia de que los conocimientos tienen diferentes, manifestaciones, ámbitos y que hay polifonía de tonalidades que rompen con los parámetros rígidos de concebir al mundo y a la realidad.

El concepto de formación de sujetos sociales, por lo tanto, está ligado, sustantivamente, con el concepto de apertura, ya que éste nos permite abrirnos a las realidades históricas y al sujeto mismo, para desentrañar su capacidad de actuar con voluntad y con emoción dentro de las realidades y circunstancias que ofrece el presente potencial.

Esta apertura ante la realidad nos permite potenciar al sujeto para convertirlo en actor de su propia transformación, en constructor de conocimiento y en la necesidad ineludible de ser sujeto de su propia construcción, para que asuma la conciencia de conocerse en el proceso mismo de conocer y transformar la realidad. Esto significa querer sabernos conscientes y poder, de esta manera, reanudarnos con el mundo.

\footnotetext{
14 BOISVERT, Jacques. (2004): La formación del pensamiento crítico. Teoría y práctica, México, Fondo de Cultura Económica, p. 25.

${ }^{15}$ CAMPOS Arenas, Agustín. (2007): Pensamiento crítico. Técnicas para su desarrollo, Bogotá, Cooperativa Editorial Magisterio, p. 13.
} 
La apertura también requiere de postura, de situarse desde un determinado ángulo para construir conocimiento, de ubicar ese conocimiento que construye en perspectiva social y en opciones de vida. Construir conocimiento, en este sentido, no es una pose intelectual efímera, sino una necesidad de producción de sentido y de construcción de horizontes posibles para avivar la llama de la conciencia como necesidad de mundo. Las ideas aquí analizadas las podemos ver con claridad en Paulo Freire, cuando manifiesta:

Una de las tareas más importantes de la práctica educativo-crítica es propiciar las condiciones para que los educandos en sus relaciones entre sí $y$ de todos con el profesor o profesora pueden ensayar la experiencia profunda de asumirse. Asumirse como ser social e histórico, como ser pensante, comunicante, transformador, creador, realizador de sueños, capaz de sentir rabia porque es capaz de amar. Asumirse como sujeto porque es capaz de reconocerse como objeto. La asunción de nosotros mismos no significa la exclusión de los otros. Es la "otredad" del "no yo" o del tú, la que me hace asumir el radicalismo de mi yo. ${ }^{16}$

Paulo Freire, reclama, entonces, que el sujeto se convierta en eje vertebrador para que pueda avanzar en la construcción de realidades para saberse colocar, tanto en la historia-mundo, como en la autoconciencia de ser sujeto constructor de conocimiento, de conciencia y de su propia vida. La realidad, construya como tal. El sujeto, en este sentido, es un emergente portador de futuro, es un sujeto que se va haciendo a sí mismo, y a la vez, descubriendo que con su proceso formativo va ganando espacios que le permitan gestar mundos posibles, interrogando a la realidad con sus preguntas como necesidad perentoria del espíritu humano.

En ese proceso de interrogar a la realidad, la problematiza, es decir, la convierte en problema, en obstáculos, en límites que hay que empujar o derribar. Esta provocación de problemas no puede darse en forma ingenua o espontánea, sino con sentido crítico y con intencionalidad de conocer, y en ese proceso, potenciar la capacidad de escudriñar lo no explorado y asumirse como portador de pensamientos con propósito de apropiarse de la realidad objeto de sus indagaciones para explicarla o comprenderla.

Ahora bien, como colofón a este apartado, el gran interés de Paulo Freire, frente al fomento del pensamiento crítico, era la búsqueda de un proceso formativo que tuviera en cuenta la reflexión y la transformación de la práctica pedagógica para formar seres humanos como sujetos, que sean capaces de crearse a sí mismos, tanto en el campo de lo individual, como en lo colectivo. Ese ser humano-sujeto podrá resistir y afirmarse en su libertad para crear y transformar su entorno, remarcando, necesariamente, su autonomía, para querer ver, para buscar lo inédito, para romper límites y parámetros, en fin, para asumirse como sujeto crítico, creador de historia y de su propia biografía personal.

${ }^{16}$ FREIRE, Paulo. (1998): Pedagogía de la autonomía. Op. Cit, p. 42. 


\section{Reconocimiento y Respeto de la Diversidad de Saberes}

Hemos venido desarrollando la idea, apoyados en el espíritu que inspira la obra de Paulo Freire, de que los sujetos constructores de conocimientos lo hacen desde distintas motivaciones, experiencias, historias, herencias culturales y reflexivas; de la misma manera, los sentidos y los significados que le imprimen a sus producciones llevan el sello de sus interacciones dadas en tiempos, espacios y escenarios que los condicionan. Si a lo anterior le sumamos los deseos, los intereses, las experiencias, los sueños y las perspectivas de saberes que se hacen patentes en referentes económicos, políticos y sociales, tendremos una intrincada madeja de construcción de identidad individual y colectiva que hacen que sus producciones sean únicas y específicas.

Querer interpretar lo ajeno es de suma complejidad, porque se pretende dar cuenta de las realidades del otro en sus diferencias y afinidades, expresadas en códigos, símbolos, imaginarios, prácticas y experiencias diversas desde la perspectiva de quien lo hace. Emma León Vega, muestra la complejidad en las ideas relacionadas: “... se trataría de colocarnos ante nuestras circunstancias y formación para desafiar, con los medios que tenemos la lectura que se ha hecho de nuestros encuentros con la Otredad. Si uno de estos medios es la propia producción intelectual y reflexiva, los lenguajes disciplinarios, los registros y las crónicas acumuladas en el vasto continente de la experiencia social y cultural, entonces tendremos que tomarlos y seleccionar entre ellos a aquellos que, con sus limitaciones, nos ofrecen un cúmulo de herramientas para comenzar a desbaratar esa cerradura rígida y adherente de nuestros esquemas de sensibilidad, percepción e interpretación."17

Pero nuestra "cerradura rígida y adherente de nuestros esquemas de sensibilidad, percepción e interpretación", tanto en sus orígenes y desarrollos, no es un elemento que se forma fuera del contexto relacional de los individuos entre sí, está enraizado en la matriz experiencial de los individuos portadores de las mismas, y por lo tanto, ella no puede ser interpretada por fuera de sus condicionamientos históricos y su intrincadas relaciones vitales. En este sentido, el reconocimiento y el respeto a la diversidad de saberes se convierten en uno de los ejes fundamentales de la propuesta de Paulo Freire, así lo expresa con toda claridad:

Por eso mismo pensar acertadamente impone al profesor o, en términos más amplios, a la escuela, el deber de respetar no sólo los saberes con que llegan los educandos, sobre todo los de las clases populares -saberes socialmente construidos en la práctica comunitaria-, sino también, como lo vengo sugiriendo hace más de treinta años, discutir con los alumnos la razón de ser de esos saberes en relación con la enseñanza de los contenidos. ${ }^{18}$

Y es verdad, ya desde la publicación en español de Pedagogía del oprimido en

17 LEÓN, Emma. (2005): Op. Cit, p. 92.

18 FREIRE, Paulo. (1998): Pedagogía de la autonomía. Op. Cit, p. 31. 
1970, Paulo Freire introduce una categoría sumamente sugestiva, la cual la apellida "bancaria" para referirse a las concepciones y prácticas opresoras que se dan tanto en la escuela como en el contexto general de lo político y social; de manera explícita así lo indica:

En la visión "bancaria" de la educación, el "saber", el conocimiento, es una donación de aquellos que se juzgan sabios a los que juzgan ignorantes. Donación que se basa en una de las manifestaciones instrumentales de la ideología de la opresión: la absolutización de la ignorancia, que constituye lo que llamamos alienación de la ignorancia, según la cual ésta se encuentra siempre en el otro. ${ }^{19}$

Esta perspectiva homogeneizadora busca por todos los medios opacar, debilitar o negar la autonomía de los individuos, en pos de dominarlos, invisibilizarlos o explotarlos; ejerciendo, de esta manera, colonialismo material, mental y simbólico, poniéndole cerrojos a la Otredad, cosificando las relaciones y haciendo que los espacios de encuentros pedagógicos se petrifiquen y se conviertan en depósitos para ser llenados dócilmente.

La denuncia que hace Paulo Freire, es sumamente diciente:

El educador que alienta la ignorancia, se mantiene en posiciones fijas, invariables. Será siempre el que sabe, en tanto que los educandos serán siempre los que no saben. La rigidez de esas posiciones niega a la educación $y$ al conocimiento como procesos de búsquedas. ${ }^{20}$

Esta actitud niega al otro como sujeto, lo cosifica, lo vuelve un extraño ante sí mismo y frente a los demás, la coexistencia humana se distorsiona y pierde su valía y su significación, en la medida en que está determinada en forma heterónoma y avasalladora. En el caso concreto del enseñar y del aprender, esta actitud es invasora y mata lo más significativo de las vivencias humanas: el deseo. Éste, que como acicate, como combustible detonador, nos impulsa a la acción y a las grandes realizaciones. Sin deseo no hay aprendizaje verdadero. Pero en la relación pedagógica signada como "bancaria", "el educador es el sujeto del proceso; los educandos, meros objetos". "Si el educador es quien sabe, y si los educandos son los ignorantes, le cabe, entonces, al primero, dar, entregar, llevar, trasmitir su saber a los segundos. Saber que deja de ser un saber de "experiencias realizadas" para ser el saber de experiencias narradas o trasmitidas." 21

Frente a esta perspectiva avasalladora, Paulo Freire, propone la "dialogicidad" como elemento sustantivo y necesario de una educación problematizadora, como práctica de la libertad, indicando:

19 FREIRE, Paulo. (1998): Pedagogía del Oprimido. Op. Cit, p. 73

${ }^{20}$ Ibídem, p. 74.

${ }^{21}$ Ibídem, p. 74. 
Nubia Agudelo - Norman Estupiñan

De este modo el educador ya no es sólo el que educa sino aquel que, en tanto educa es educado a través del diálogo con el educando, quien, al ser educado, también educa. Así, ambos se transforman en sujeto del proceso en que crecen juntos y en el cual "los argumentos de la autoridad" ya no rigen. Proceso en el que ser funcionalmente autoridad, requiere el estar siendo con las libertades y no contra ellas. ${ }^{22}$

Entonces, como reconocimiento indispensable para los sujetos que participan en el proceso educativo, se hace necesaria la fundamentación del diálogo de saberes como dispositivo hermenéutico que permita la reflexividad y la configuración de relaciones pedagógicas con significación y sentido. Esta situación dialógica está encaminada a ganar poder para la libertad en el proceso de la construcción de subjetividades, en donde los sujetos sociales y pedagógicos vayan tejiendo la madeja de la urdimbre de posibilidades en los espacios escolares y culturales en pos de la fabricación de simbologías compartidas, espacios normativos y marcos interpretativos que conlleven a fomentar la participación y a establecer lazos democráticos y al ojo más, en el sentido de Amartya Sen y Bernardo Kliksberg: "esto también debería conducirnos hacia el reconocimiento de la capacidad de los seres humanos para pensar juzgar por sí mismos - una capacidad que ahora valoramos y una libertad que quisiéramos preservar para el futuro"23

Construir identidad colectiva, entonces, conlleva rupturas, alteraciones, reordenamientos, compartir ideologías, representaciones sociales, objetivos, valores y sentimientos. En este proceso los sujetos se asumen y se potencian en el entramado de las relaciones. Pero este acontecimiento no se puede dar sin el otro, puesto que la construcción social de los sujetos no es un proceso aislado, antes por el contrario, está inscrito en lo más profundo de las relaciones históricas y sociales de una matriz cultural determinada.

De esta manera, el diálogo de saberes está reclamando la valoración del otro, la ponderación de la intersubjetividad, la cual es la fuente del quehacer pedagógico. Los sujetos al relacionarse permiten los encuentros interculturales, tejiendo la trama de sus realizaciones en escenarios institucionales. Este es un encuentro de seres humanos, de seres creativos, de seres diversos que pueden transformar situaciones, escenarios y saberes. Al decir de Paulo Freire:

No puedo comprender a los hombres y las mujeres más que simplemente viviendo, histórica y socialmente existiendo, como seres que hacen su camino y que, al hacerlo, se exponen y se entregan a ese camino que están haciendo y que a la vez los rehace a ellos mismos. ${ }^{24}$

Retomando el concepto de diálogo de saber en Paulo Freire el cual hemos venido presentando, podemos cerrar este aparte diciendo: Las ideas anteriores están reclamando

\footnotetext{
22 Ibídem, p. 86.

${ }^{23}$ SEN, Amartya y KLIKSBERG, Bernardo. (2007): Primero la gente una mirada desde la ética del desarrollo a los principales problemas del mundo globalizado, España, Ediciones Deusto, p. 58.

${ }^{24}$ FREIRE, Paulo. (1998): Pedagogía de la esperanza, México, Siglo XXI Editores, p. 93.
} 
actores sociales que se conviertan en sujetos históricos, y protagonistas de sus propios proyectos sociales, pedagógicos y culturales, acordes con sus intereses y necesidades. Sujetos que hagan posible procesos colectivos, en donde se puedan potenciar las subjetividades para la consolidación de espacios solidarios, solidaridad que promueva cambios de valores, que impulsen la conciencia crítica, el dinamismo participativo y que estimule el disfrute de lo estético y que haga posible la expresión de la dignidad humana en todos sus matices y en todas sus dimensiones. Creemos que esto es posible si en los espacios y encuentros pedagógicos y sociales, se aprovechan las diferentes energías culturales de todos los participantes, evitando el desperdicio de las mismas, y se potencian las diferentes vibraciones que las acciones humanas producen cuando se anudan en redes sociales.

\section{Preocupación por los Otros}

Toda la sensibilidad intercultural de Paulo Freire estuvo orientada a la preocupación por los otros. Ese Otro, que con mucha maestría caracteriza Emma León Vega, y que con toda propiedad lo podemos traducir a la vida y a la obra de Paulo Freire: En su límite, todos somos el Otro, pues éste es nuestro espejo constitutivo en relación con el cual nos definimos. Cruzar la frontera significa que mi morada se nutre y sostiene de los diálogos y disputas con el Otro. Ella es el espacio donde se accede al reconocimiento propio a través del conocimiento ajeno, pero la subjetividad de quien vive en los bordes también es una subjetividad herida, quebrada: es la subjetividad de la no-pertenencia cabal y también la alteridad que permite develar lo oculto y lanzar una mirada lúcida sobre la opacidad de lo establecido. Simultáneamente, es conciencia de los efectos de cruzar los bordes. Vivir en la frontera es pérdida provisional y carencia de certezas, pero así mismo distancia y contrapunto a todo universo acabado o perfecto. La frontera nos encierra en la seguridad de un territorio familiar, pero también puede convertirse en prisión, al ser defendida más allá de toda razón y necesidad. "Quien vive en los bordes, se niega así, implícitamente, a pertenecer." ${ }^{25}$

Paulo Freire, en su vida y en su obra, siempre fue un trasgresor de fronteras para nutrirse a través del diálogo y disputas con el Otro. Testimonios múltiples así lo confirman. Por ejemplo, Ana María Araujo Freire, esposa de Paulo, afirma:

Freire se forja, por la praxis vivida, como pedagogo del oprimido incluso sin haber escrito la Pedagogía del oprimido porque partía del saber popular, del lenguaje popular, de la necesidad popular, respetando lo concreto de ellos, lo cotidiano de las limitaciones de ellos. Además de eso, no se quedaba en el punto de partida, sino que presentaba una propuesta de superación de este mundo de sumisión, de silencio y de miserias, señalando un mundo de posibilidades. ${ }^{26}$

\footnotetext{
25 LEÓN VEGA, Emma. (2009): Los rostros del otro. Reconocimiento, invención y borramiento de la alteridad. Barcelona, Anthropos, p. 10.

26 ARAUJO FREIRE, Ana María. (2001): La voz de la esposa: La trayectoria de Paulo Freire. en Paulo Freire una biobibliografia. GARDOTTI, Moacir y TORRES Carlos Alberto, México, Siglo XXI Editores, p. 20.
} 
Nubia Agudelo - Norman Estupiñan

De la misma manera, Ettore Gelpi, amigo y estudioso de Freire, asevera que: "De nuevo el encuentro con un hombre que escucha, interesado, amante de la vida y siempre dispuesto, no obstante, sin concesión fácil al discurso."27

Por lo demás, Moacir Gadotti, estudioso ferviente y sistemático del pensamiento, vida y obra de Freire, nos recuerda:

El pensamiento de Paulo Freire-su teoría del conocimiento - debe entenderse en el contexto en que surgió - el Nordeste brasileño, donde, al comienzo de la década de 1960, la mitad de sus de sus 30 millones de habitantes vivía en la "cultura del silencio", como él decía, o sea, eran analfabetos. Era necesario "darle la palabra" para que "transitasen" hacia la participación en la construcción de un Brasil que fuese dueño de su propio destino y que superase el colonialismo. ${ }^{28}$

Ahora bien, si a los anteriores testimonios les agregamos las propias aseveraciones de Paulo Freire, tendremos un panorama más completo frente a la intencionalidad manifiesta del autor de su preocupación por los otros. Por ejemplo, en Pedagogía del oprimido, así lo expresa:

Las afirmaciones sostenidas a lo largo de este ensayo, desposeídas de todo carácter dogmático, no son frutos de meros devaneos intelectuales ni el solo resultado de lecturas, por interesantes que estas fueran. Nuestras afirmaciones se sustentan siempre sobre situaciones concretas. Expresan las reacciones de problemas urbanos, campesinos y hombres de clase media a los que hemos venido observando, directa o indirectamente, a lo largo de nuestro trabajo educativo. Nuestra intención es la de continuar con dichas observaciones a fin de realizar o rectificar, en estudios posteriores, puntos analizados en este ensayo. ${ }^{29}$

De la misma manera, en Pedagogía de la esperanza, Paulo Freire remarca su preocupación por los otros, de la siguiente forma:

Trabajaba entonces en el SESIy, preocupado por las relaciones entre escuela y familia, venía experimentando caminos que mejor posibilitasen su encuentro, la comprensión de la práctica educativa realizada en las escuelas, por parte de las familias, la comprensión de las dificultades que tendrían las familias de las áreas populares, enfrentando problemas, para realizar su

\footnotetext{
27 GELPI, Ettore. (2001): Un hombre dotado de una gran humanidad. en Paulo Freire una biobibliografia GARDOTTI, Moacir y TORRES Carlos Alberto, México, Siglo XXI Editores, p. 221.

28 GADOTTI, Moacir. (2001): La voz del biógrafo brasileño La practica a la altura del sueño, en Paulo Freire una biobibliografia GADOTTI, Moacir y TORRES Carlos Alberto, Siglo XXI Editores. México, p. 51.

${ }^{29}$ FREIRE, Paulo. (1998): Pedagogia del Oprimido, Op. Cit, p. 22.
} 
actividad educativa. En el fondo lo que buscaba era un diálogo entre ellas del que pudieran resultar la necesaria ayuda mutua que por otro lado, al implicar una intensidad mayor de la presencia de las familias en las escuelas, pudiera ir aumentando la connotación política de esa preocupación en el sentido de abrir más canales de participación democrática a padres y madres de la propia política educacional vivida en las escuelas. ${ }^{30}$

Ahora añadiremos otra intencionalidad manifestada por Paulo Freire. Nos estamos refiriendo a la Pedagogía de la autonomía, en la cual con toda claridad expresa la preocupación por el otro, cuando dice:

La cuestión de la formación docente junto a la reflexión sobre la práctica educativa progresista en favor de la autonomía del ser de los educandos es la temática central en torno a la cual gira este texto. Temática a la que se incorpora el análisis de los saberes fundamentales para dicha práctica y a los cuales espero que el lector crítico añada algunos que se me hayan escapado o cuya importancia no haya percibido. ${ }^{31}$

Podemos cerrar este aparte con las palabras de Tzvetan Todorov: "Cuando renunciamos a privilegiar siempre nuestro punto de vista en las relaciones sociales, nos acercamos a los otros." 32

\section{Pensamiento de Frontera}

Definitivamente, Paulo Freire es un hombre límite, un hombre frontera, un hombre que habita los bordes. Todos los testimonios anteriores así lo confirman, tanto desde las perspectivas de los familiares y amigos, como desde las aseveraciones que él mismo produce. Así, la esperanza es la frontera entre la rabia y el amor. La rabia de sentir y de pensar a los oprimidos, pero el amor por su liberación. Es límite entre la realidad y la utopía, sin ésta no hay perspectiva de búsqueda, pero sin aquella la praxis es vacía y sin asidero. Frente a estas ideas, León Vega aporta:

Este hombre-límite, es un ser "cambiante y volátil, se goza en la falta de arraigo, en la flexibilidad y movilidad. Altivo y orgulloso, este hombre se sabe capaz de cualquier sacrificio; sabe que su tenacidad es capaz de vencer cualquier obstáculo que la naturaleza le ponga. Más aún: no resiste la tentación de doblarle la mano para obligarlo a revelar sus secretos aunque, removidas las huellas por otras huellas, parecieran ocultarse. ${ }^{33}$

\footnotetext{
${ }^{30}$ FREIRE, Paulo. (1998): Pedagogía de la esperanza, Op. Cit, p. 18.

${ }^{31}$ FREIRE, Paulo. (1998): Pedagogía de la autonomía, Op. Cit, p. 15.

32 TODOROV, Tzvetan. (2008): El miedo a los bárbaros, Galaxia Gutenberg, Círculo de lectores. p. 41

${ }^{33}$ LEÓN, Emma. (2005): Op. Cit, p. 20.
} 
De la misma manera, las ideas expuestas las podemos apreciar en el juego muy serio a que "Moacir Gadotti" ${ }^{34}$ sometió a Paulo Freire para auscultar sobre sus virtudes, defectos y preferencias. Así, pues, las cualidades que más aprecia en las personas, son: coherencia, decisión, ternura. Su rasgo característico, tolerancia. Su ideal de felicidad, lucha. Su idea de desgracia, opresión. Su antipatía, intelectual arrogante. Su ocupación predilecta, enseñar-aprender.

Ese hombre-frontera, coherente, decidido, tierno, tolerante, luchador y enemigo acérrimo de la opresión y de la arrogancia, se movió en el proceso de enseñar y aprender para hacer que los seres humanos recorrieran el camino de la libertad. Pero no de una libertad en abstracto, sino de la necesidad perentoria de conocer para transformar. Impulsar el deseo de saber, para tomar conciencia de la opresión.

Recogiendo lo antes expresado y como posibilidad de concluir este aparte, defendemos la tesis de que Paulo Freire se movió entre esos límites asimétricos de la realidad y la utopía, entre la dispersión y la búsqueda de coherencia, entre lo nómada y lo estático, entre la dispersión y la mezcla, una forma de doble plano: entre las vivencias cotidianas de la opresión y los sueños posibles de transformación. La preocupación por el Otro está llena de ausencias, de silencios, de voces apagadas, de realizaciones maltrechas, pero la utopía de su transformación también es otro extranjero, que no ha sido reconocido y debe ser interpelado constantemente para que no se apague la llama que lo vivifica. Como expresa Homi Bhabha "Es en este sentido que el límite se vuelve el sitio desde el cual algo comienza a presentarse en un movimiento no distinto a la articulación ambulante y ambivalente del más allá que he trazado.”35

\section{CONCLUSIÓN}

La sensibilidad intercultural de Paulo Freire es un campo que se abre a la investigación y al debate de la comunidad académica. El pensamiento de este educador transitó por los entreveros del entendimiento del otro como posibilidad de ser y llenarse de humanidad. En este sentido, la galaxia cultural de lo humano lo inundó de sentido y de significación: su curiosidad, su pensamiento crítico, el diálogo de saberes y la preocupación por el otro, fueron un constante desafío en su obra y en su vida. El diálogo como eje central de los encuentros humanos, tiene la virtud del rescate de la palabra, pero debe ser alimentado por el silencio. Éste, no como ausencia de palabra, sino como espacio en donde aquella cobra su expresividad. Además, proponemos al autor en mención, ir más allá del diálogo dialéctico, para inscribirse en el "diálogo dialogal", el cual no pretende convencer al otro, ni vencerlo dialécticamente, sino, crear un espacio de confianza en donde la verdad sea posible.

\footnotetext{
${ }^{34}$ ARAUJO FREIRE, Ana María. (2001): Op. Cit, p. 46.

${ }^{35}$ BHABHA, Homi K. (2002): El lugar de la cultura, Argentina, Ediciones Manantial SRL, Buenos Aires, p. 21.
} 


\section{FUENTES}

FREIRE, Paulo. (1998): Pedagogía del Oprimido, México, Siglo XXI Editores. (1998): Pedagogía de la esperanza, México, Siglo XXI Editores. (1998): Pedagogía de la autonomía, México, Siglo XXI Editores.

\section{SELECCIÓN BIBLIOGRÁFICA}

BHABHA, Homi K. (2002): El lugar de la cultura, Buenos Aires, Argentina, Ediciones Manantial SRL.

BOHM, David. (1997): Sobre el diálogo, Barcelona, Editorial Kairós.

BOISVERT, Jacques. (2004): La formación del pensamiento crítico, México, Teoría y práctica. Fondo de Cultura Económica.

CAMPOS Arenas, Agustín. (2007): Pensamiento crítico, Técnicas para su desarrollo, Bogotá Cooperativa Editorial Magisterio.

GADOTTI, Moacir y TORRES Carlos Alberto. (2001): Paulo Freire una biobibliografia, México, Siglo XXI Editores.

LEÓN VEGA, Emma. (2005): Sentido ajeno. Competencias ontológicas y otredad, Barcelona, Anthropos.

(2009): Los rostros del otro. Reconocimiento, invención y borramiento de la alteridad, Barcelona, Anthropos.

LLOYD, Geoffrey. (2008): Las aspiraciones de la curiosidad. La comprensión del mundo en la antigüedad: Grecia y China, España, Siglo XXI Editores S.A.

PANIKKAR, Raimon. (2006): Paz e Interculturalidad, una reflexión filosófica, España, Herder Editorial.

SEN, Amartya y KLIKSBERG, Bernardo. (2007): Primero la gente una mirada desde la ética del desarrollo a los principales problemas del mundo globalizado, España, Ediciones Deusto.

TODOROV, Tzvetan. (2008): El miedo a los bárbaros, Galaxia Gutenberg, Círculo de lectores.

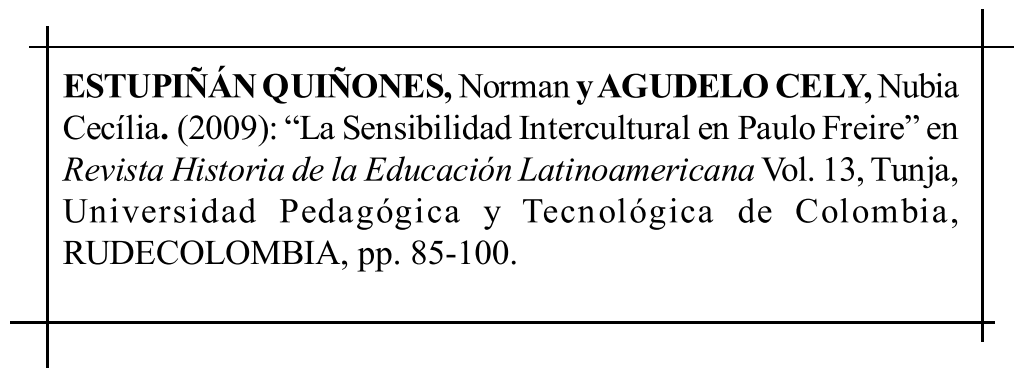

Rhela. Vol. 13. Año 2009, pp. 85 - 100 